Technological University Dublin

DÜBLIN

ARROW@TU Dublin

2010-01-01

\title{
The Benefits of Holidaying for Children Experiencing Social Exclusion: Recent Irish Evidence
}

\author{
Bernadette Quinn \\ Technological University Dublin, bernadette.quinn@tudublin.ie \\ Jane Stacey \\ Technological University Dublin
}

Follow this and additional works at: https://arrow.tudublin.ie/tfschhmtart

Part of the Social Work Commons, and the Sociology Commons

\section{Recommended Citation}

Quinn, B., Stacey, J.:The Benefits of Holidaying for Children Experiencing Social Exclusion: Recent Irish Evidence. Leisure Studies, Vol. 29, no.1, 2010 pp.29-52. doi:10.1080/02614360903046631

This Article is brought to you for free and open access by the School of Tourism \& Hospitality Management at ARROW@TU Dublin. It has been accepted for inclusion in Articles by an authorized administrator of ARROW@TU Dublin. For more information, please contact arrow.admin@tudublin.ie, aisling.coyne@tudublin.ie, gerard.connolly@tudublin.ie.

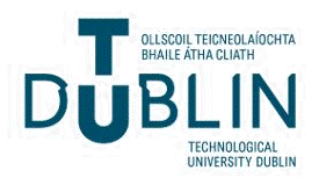


Quinn, B. and Stacey, J. (2010) The benefits of holidaying for children experiencing social exclusion - recent Irish evidence, Leisure Studies 29 (1): 29-52. 


\section{Introduction $^{1}$}

Recently, there has been a strong increase in investigating what Scheyvens (2007) has called the tourism-poverty nexus. Much of the ensuing literature has focused on poverty in developing world contexts and on tourism's potential as a strategy for poverty alleviation therein. However, another important dimension to the tourism-poverty nexus concerns the links between tourism and social exclusion in affluent societies. It has long been recognised that holidaying is a practice that is not equally available to all and that variations in income, time availability, gender, race and nationality constrain and structure access to holiday time and travel opportunities (Davidson 1996, Richards 1998). Ianniello's (2006) reporting of data gathered from national tourism agencies across 16 EU states show that holiday non-participation rates range from $11.7 \%$ in Sweden to upwards of $30 \%$ in Belgium, France and the UK and to more than $45 \%$ in Portugal, Spain, Greece, Hungary, Poland and Slovakia. Reasons identified for this nonparticipation are varied but financial factors predominate, a finding that is in line with previous research (English Tourist Board (ETB) 1985, European Commission 1998, 2001, Eurobarometer 1998, Haukeland 1990, Hughes 1991, Jolin 2004). Other factors which prevent people from having a holiday include illness and disability (physiological and psychological), mobility and access, family circumstances, caring for dependents and problems associated with aging and gender (ETB 1989, Shaw and Williams 2002). Many of these other constraining factors overlap with the economic variable in producing social marginality and exclusion (Van Raaji and Francken 1984, ETB 1989, Seaton 1992, Shaw and Williams 2002).

Thus, it seems that while the incidence of holiday-taking continues to rise, as evidenced in repeated World Tourism Organization reports, holiday participation rates remain constrained. Richards' (1998: 156) suggestion is that in Europe, the 'growth in demand is due to a concentration of consumption, rather than an extension of consumption to all social groups'. He further suggests that a polarisation of holiday-taking mirrors the polarisation of incomes. Richards (1998: 158) concludes that 'a ceiling appears to have

\footnotetext{
${ }^{1}$ Bernadette Quinn, Department of Tourism, DIT, Cathal Brugha St. Dublin 1 and Jane Stacey, Tourism Research Centre, DIT, Marlborough St. Dublin 1.
} 
been reached in many countries in the proportion of the population who can take holidays in any one year'. Jolin (2004) suggests that in the majority of Western countries, this ceiling may be somewhere between $50-60 \%$ of the population, despite the rise of mass tourism and various state initiatives to promote access to tourism.

Very recently, there has been a renewed interest in viewing tourism as an exclusionist practice. Two special issues of Tourism, Culture \& Communication in 2005 and 2006 took up the theme, while Current Issues in Tourism has a forthcoming special issue on the topic. Higgins-Desbiolles (2006), meanwhile, recently argued that so long as tourism continues to exclude sectors of society, its potential to create individual and collective social benefits will remain unrealised. To date, there have been inferences in the literature that a lack of holiday opportunities may compound social deprivation, reinforce social problems and heighten social exclusion. Hazel (2005), for example, has argued that the risk of holiday non-participation leads to a feeling of deprivation and social exclusion in young people and others. Furthermore, as Hughes (1991) suggests, it may be those most in need of a holiday that are being excluded. Elsewhere, Haukeland (1990) claimed that non-participation in holidays may be a social welfare issue with health and social care implications for children and families.

This paper follows Hughes (1991: 196) in arguing that 'holidays cannot be dismissed lightly as a frivolous pursuit' but should be seen 'more as an investment in the well-being and social fabric' of society. It draws from a wider study that argues for the development of policy to broaden access to tourism in Ireland. The study aimed to investigate the benefits that widening access to holidaying among socially excluded groups, and particularly among children, might generate. In so doing it seeks to address gaps in the literature pertaining to those experiencing social exclusion in general (Hazel 2005, Corlyon and La Placa 2006) and to children and young people in particular (Lewis 2001). A related objective was to investigate the extent to which an ability to participate in holidaying can help build social capital and in the process, help to alleviate social exclusion. The next section of the paper discusses the links between holidaying, social exclusion and social capital, and reviews extant knowledge about how holidaying can 
benefit those experiencing social exclusion. It then briefly reviews the broader literature on holidaying and well-being. The key research question posed is how can access to an annual holiday contribute to quality of life and help combat social exclusion for children, and the families of children, experiencing poverty? The findings of qualitative research undertaken among a group of families experiencing social exclusion in Ireland's capital city, Dublin, are discussed and the paper ends by considering implications for future research.

\section{Holidaying, social exclusion and social capital}

As Corlyon and La Placa (2006) explain, social exclusion is a relatively new term that embraces both the causes and effects of poverty. They cite the UK government's definition of social exclusion as: 'A short hand label for what can happen when individuals or areas suffer from a combination of linked problems such as unemployment, poor skills, low incomes, poor housing, high crime environments, bad health and family breakdown' (UK Department for Social Security 1999: 23). Micklewright (2002) follows Atkinson (1998) in highlighting three important defining aspects of social exclusion: relativity, agency and dynamics. Relativity communicates the idea that people are excluded from a particular society and that exclusion can only be gauged relative to that society. Agency implies that people are excluded by an act of some agent, while dynamics portrays the idea that exclusion refers not only to an individual's current circumstances but also to the bleakness of their future prospects.

While there is an extensive and longstanding literature on the social impacts of tourism (e.g. Mathieson and Wall, 1982), few researchers have specifically linked holidaying as a social practice with social exclusion. This is despite that fact that the established social normalcy of holidaying in advanced capitalist societies has been recognized for quite some time now. A UK study published in 1985 (Mack and Lansley), for example, found that $63 \%$ of the adult population surveyed considered a one week annual holiday to be a necessity. In 1995, Urry wrote that being able to take a holiday was presumed to be a characteristic of modern citizenship. Smith and Hughes (1999) echoed this in their study

of disadvantaged families, arguing that 'limited access to leisure and / or holidays can be 
seen as exclusion from a common way of life and from 'needs' which everyone has the right to be met in order to become a full citizen of one's society. As Holden (2005: 53) later explained, because holidaying has increasingly become 'more of an expected experience rather than a luxury', an inability to participate in holidaying effectively means an inability to participate in 'the mainstream lifestyle of a community'. For tourism researchers, a key question that needs to be addressed is whether engaging in the social practice of holidaying can help to combat social exclusion and so promote social inclusion.

While this question is not commonly considered in the literature, research on the benefits of holidays has empirically investigated socially excluded groups since at least the 1970s. An early study, conducted by the English Tourist Board (ETB), evaluated a program designed to give socially-deprived people in London boroughs an opportunity to go on holiday. It found that the holidays provided value in terms of social well-being and relief for caring relatives, as the holidays were found to provide an essential break for carers who suffered from emotional, mental and physiological stress. More recently, the majority of GPs who participated in an English Tourism Council study (Voysey 2000) claimed that holidays were beneficial in alleviating the problems that stem from poverty, isolation, lack of family/community support, stress at work and living in an unsafe neighborhood. They considered holidays to have a strong covert influence on health and well-being and quality of life. They further considered that holiday participation mitigates against family or relationship breakdown.

The literature on the effects of holiday participation for children has also specially investigated how engagement in holidaying can be a means of promoting engagement with mainstream society and of promoting social inclusion. Buin, (cited by Lauprêtre, 2006) for example, concluded that non-participation 'risks cutting these children off from others who have developed this culture of travelling' Another study of young people in care by Lewis (2001) revealed that these young people 'were aware of their social exclusion and felt that they were missing out on holidays that other children were able to experience'. Similar work by Ridge (2002) found that children from poor families can be 
made to feel different and unable to participate fully in life and school activities (trips, projects etc.) because of their family's lack of financial resources. The argument that children's experiences of poverty can be heightened through comparison with peers is strongly made by Van der Hoek (2005) whose Dutch research found that children's inability to access holidays was particularly problematic for this reason: 'for them the impact was felt not just in the lack of a holiday itself but also by social comparison with their peers who were able to go away during school holidays' (2005: 18). Thus, the experience of the summer holidays can be one of heightened exclusion (Gill and Wellington 2003), as the majority experience of holidays, events, activities and trips is reflected in media images to which all children are exposed. Indeed, Gill and Wellington (2003), who studied families in income-deprived households, note that for children in poverty, these activities are simply outside the resources of their families and the summer holidays become a time of 'survival'.

The studies cited directly above explicitly demonstrate how an inability to engage in holidaying constitutes exclusion from a mainstream, meaningful, social practice. Once excluded, those affected have little opportunity to access the social capital generated through participation in holidaying. In tourism research, the modest literature that addresses social capital tends to focus on how the existence of social capital in a place is implicated in fostering tourism development (e.g. Jones 2005, Macbeth, Carson and Northcote 2004). Rarely has attention focused on investigating how participation in tourism activities helps to develop social capital. Social capital refers to the bank of resources built up through interpersonal networks and associations upon which individual members of a community can draw (Macbeth, Carson and Northcote 2004). In order to draw on social capital, a person must be connected to other people who become the actual source of his/her advantage (Portes 1998). As Jones (2005) points out, this social networking and connectivity 'develop shared norms, trust and reciprocity' that in turn foster cooperation to achieve common ends (Ecclestone and Field 2003). Participating in holidaying is premised in connectivity. Holidaying is most often practiced as a communal activity. While people may holiday alone, most travel in groups of family, friends and peers, while the globally prevalent package holiday industry is premised on group travel. 
Even if holidaying is undertaken as a solo venture, once in a destination, it is a practice that involves multiple and varied social relations. All of these interactions build social inclusion through a variety of interpersonal connections that promote a sharing of norms, experiences and knowledge. Clearly, being a tourist also means interacting with the suppliers of tourism information, products and services, whether they are located in the locale or further afield. These interactions, in turn, help create the confidence and ease that enable subsequent involvement, not only in tourism, but in a range of routine lifestyle activities that require social interaction.

Exactly how practicing holidaying builds up social capital is under-researched in the literature. Corlyon and La Placa (2006), in their study of families, implicitly refer to the value of being able to draw on holidaying experiences when they describe how the actual process of taking a holiday for those with little experience can be difficult and stressful. Others have pointed out that in addition to financial means, certain skills are needed to be able to access a holiday (Shaw and Williams 2002, Seaton, 1992). Elsewhere, Baum (2006), in a study of air travel, suggested that the reduction of purely financial costs does not necessarily facilitate social inclusion and access. However, questions about the sort of social capital that is needed in order to engage in holidaying, and about how forms of social capital emerge through the attendant benefits of holidaying require much further research.

\section{Holidaying and well-being}

Addressing these research deficits can be furthered through the literature on what might be described as 'holidaying and well-being'. A range of tourism researchers have made claims about well-being in respect of a diverse range of study populations. According to Hobson and Dietrich (1994), there is an underlying assumption in modern society that holidays are beneficial in many ways. Generally speaking, holiday-taking is viewed as a mentally and physically healthy pursuit that contributes to human well-being (WTO 1999). Richards (1998) maintains that holidays are important not only because they provide an unbroken period of leisure time but also because the quality of time spent on holiday is different. Holidays offer relief from time and place, the key constraints of 
everyday life. More recently, Lewis (2001), in her research on young people in care, has summarised the benefits of holidaying as escaping routine, relaxation, strengthening family bonds, social interaction, educational opportunity and self-fulfillment. Gilbert and Abdullah (2002) in their study of holidaying and non-holidaying adults, also argued that holiday-taking is associated with enhanced well-being and life satisfaction.

In a review of the literature, Hughes (1991: 195) claimed that 'holidays can perform real functions that are beneficial to both individuals and society'. Some researchers have speculated that the benefits accruing to the individual and the family can contribute to financial and social benefits for society in general (Corlyon and La Placa 2006, Hazel 2005). Hazel (2005), for example, suggested that improved access to holidays could reduce the pressure on health and social services, citing the Canadian Council on Social Development (1984) which found that holiday participation improved relationships, reduced drug abuse and mitigated against youth crime. Benefits might also reduce the societal burden of children becoming involved in drug abuse or youth crime (Stephenson 2000; ETB 1976, cited in Hazel 2005). Research also suggests that these social and medical benefits are more likely to be felt by the poor and disadvantaged who normally feel more stressed or isolated (ETB 1976). Voysey (2000), meanwhile, argued that increased holiday taking would reduce the burden on health and social care services, lower costs to the economy through sickness, reduce the support and intervention required by social services, enable individuals to make better use of opportunities available to them and strengthen family and community ties.

Yet, relatively little research elaborates these claims, either conceptually or empirically. Hazel (2005) argues that the reason there has been so little research on the benefits of holidaying is precisely because of the broadly accepted assumption that holidaying is good for everyone. Underlying this assumption, however, are a number of issues that require further explanation. An important matter rarely clarified, for instance, is the definition of the word 'holiday'. While Hazel (2005) suggests that 'holiday' is most commonly defined in literature and policy as a recreational break of four or more nights away from home, very often, researchers use the term in a very generic way and without 
consistent reference to defining criteria like duration, location, group composition, etc. This creates a degree of vagueness about the resultant outcomes identified. This critique is important particularly because some of the literature presents evidence to suggest that the benefits of a holiday can extend beyond the time-frame of the holiday itself. The ETB (1976), for example, investigated a program designed to give socially deprived Londoners a holiday and found that anticipation prior to and memories after the holiday were considered to be almost as valuable as the holiday itself. This finding was supported by Gilbert and Abdullah (2002) in their study on the impact of holiday expectation on an individual's sense of well-being. Meanwhile Lewis (2001) reported that $67 \%$ of carers claimed that a holiday had been of particular benefit to individuals and attributed lasting benefits to young people as a result of the holiday. Brimacombe (2003) similarly asserted that the benefits last longer than the holiday and helped to develop sustainable relationships. Elsewhere, Wigfall (2004), in an evaluation of the Family Holiday Association (FHA) Family Breaks pilot project, concluded that many families experienced longer term positive outcomes. The longer term significance of a holiday was also a theme in Smith and Hughes' (1999) research on disadvantaged families. In much of the above research, however, neither the duration of these benefits nor the relative merits of a one off holiday versus regular holidays are made clear. In other cases, conflicting arguments have been made. Corlyon and La Placa (2006), in their research on families, for example, concluded that benefits are not dependent on the length of the break, positing that day trips are just as beneficial as longer holidays and in some instances, may be a better option. However, this finding is at odds with that of Voysey (2000), who indicated that while GPs felt that the health benefits of a holiday could last some time (a month for a short break, two months for a longer break), there was less consensus among GPs regarding the benefits of day trips. Equally unclear are the relative merits of one-off versus regular holiday taking. Crompton (1979) stated that long term pressure could only be reduced by regular holidaying; however this is another issue that requires further investigation.

\section{Introduction to Irish context}


Ireland is located on the western periphery of Europe. It is a country that has experienced marked social and economic change in recent decades. While its citizens number just 4.34 million, Ireland now has the fastest growing population in the EU, the country having experienced a sharp reversal in the historically embedded pattern of emigration to a current situation of net immigration. Between the start of the 1990s and the mid 2000s, the Irish economy made dramatic advances. The early 1990s witnessed the beginning of above average annual economic growth rates, a drop in unemployment from $18 \%$ in the late 1980s to $4.2 \%$ in 2005, and a drop in the Irish debt / GDP ratio from 92\% in 1993 to $28 \%$ in 2005 . Having been a net beneficiary of structural funding especially over the decade 1989 - 1999, Ireland's GDP had risen to 40\% above the EU average by 2004. Yet, despite these economic advances, critical commentators argue that Irish society remains unequal (Combat Poverty Agency (CPA) 2000), with sharp differentiation between the vulnerable class and the rest of the population (Whelan et al. 2005). The CPA (2000: 4) pointed to a growing gap between rich and poor, highlighting the damage to society: 'it is unjust and unfair, it leads to poor social cohesion and alienation and it limits choice, diversity and the ability of those on low incomes to participate in society'.

As might be expected of an economy where average incomes are amongst the highest in the world, holidaying has achieved social normalcy and is now a standard lifestyle practice in Ireland. While historically, Irish residents had one of the lowest propensities to holiday within the EU (Mergoupis, T. and Steuer, M. 2003), the number of trips being taken by Irish people is now rising rapidly, growing from 10.5 million trips (domestic and international) in 2002 to 14.3 million by 2006 (CSO 2007). This notwithstanding, SILC (EU Survey on Income and Living Conditions) data show that $22 \%$ of Irish residents did not take an annual holiday in 2006 because of a lack of financial means. In policy terms, the question of unequal access to holiday opportunities has never been addressed. Tourism in Ireland has been viewed entirely through economic lenses. While domestic market development, and the involvement of Irish residents has been a priority for decades, strategic objectives have related to wealth generation, job creation and wealth dispersion as opposed to social rights, social welfare, well-being, health or personal development. Thus, it seems very timely to problematise the socially constructed nature 
of holidaying as a lifestyle practice in the context of growing assumptions about the increasing mobility and multiple-annual holidaying practices of Irish people in popular discourse.

\section{Study Methods}

As already discussed in an earlier part of the paper, much of the literature on the benefits of holidaying treats the 'holiday' concept very generically. The research reviewed earlier dealt with different population groups (e.g. general populations, families or children living in disadvantaged circumstances, children in care) and with different holiday types (e.g. unspecified, family groups, youth groups). The research reported here studied a group of families experiencing social exclusion in Dublin city. Children from these families were given the opportunity to participate in holidays organized by three nongovernmental organisations (NGOs) working to alleviate poverty and combat social exclusion in Dublin city. The holidays were structured, child-only, child-centred holidays based in Irish holiday centres in the case of two NGOs and international destinations in the case of the third. This makes the type of holiday under study here very particular in nature. It involves only children, organized into specific age groupings (7 years-11 years; 13-15 years; and 7-16 years respectively) being taken on holiday by NGOs that operate in locus parentis for the 7 days ( in the case of the youngest age group), and 5 days (in the case of the two older groups) that the holidays lasted. Accordingly, the benefits of holidaying identified in the study are intended to relate to this specific context. While this model of holidaying is very specific, it is far from unique in Ireland, being widespread across a wide variety of school, youth club, sporting organisations and other groups such as the Scouts. A key defining trait here is that the children are selected by NGO personnel on the basis of their disadvantaged material conditions. Selection happens at the local level, with decisions taken by NGO personnel familiar with cohorts of families in specific residential areas. The logic of devising child-only holidays relates to the belief that the children who are offered holidays can benefit from being temporarily removed from the difficulties, stresses and constraints of their normal home environments. Two of the organisations, the Sunshine Fund and Teenhols, are offshoots of a much larger NGO which provides holidays to a range of groups including families, mothers and older 
people. The workings of each of the three NGOs, the Sunshine Fund, Teenhols and Darndale New Life Centre are informed by policy and practice priorities that extend well beyond the delivery of holiday services. All stem from broader organizational remits to combat poverty and material disadvantage and to promote social inclusion. All of the NGOs have long-standing track records with the Sunshine Fund, in particular, being in existence for over 80 years.

The primary research employed a number of qualitative techniques to examine the benefits that children, and by extension their families, derived from participation in these holidays. The field work was conducted between June and September 2006 and participants were drawn from a cross-section of disadvantaged areas spread across inner city and suburban Dublin. A multi-stage approach to data collection ${ }^{\mathrm{i}}$ began with a series of in-depth interviews with key informants involved in policy and practice in a variety of social, community and child-related domains. A number of pre-holiday focus groups involving 75 children and 35 guardians (representing 35 families) was designed to generate discussions around experiences of routine summer living in the participants' home place; the way the holidays were organised; the motivations/anticipation and preparations for going on holidays; prior holiday experiences; the impending holiday experience; and the differences between life on holiday and life at home. These were then followed by semi-structured individual interviews with 27 children and 16 guardians (representing 16 families) held within a two-month period following the holidays. Interview discussions closely followed the focus group themes with an additional emphasis on holiday experiences and post-holiday views and attitudes. The latter group consisted of a cross-section of participants selected on the basis of home location, household composition, income (social welfare/salary), gender and age. In addition, photographs and drawings produced by the children during the holidays (using material supplied by the researchers) proved effective in stimulating discussions and prompting children to recall holiday memories during the post-holiday interviews.

Throughout the research, due regard was given to child protection and ethical issues pertaining to conducting research with vulnerable groups. Data collection methods were 
in line with the codes of child care practice of collaborating NGOs. At the outset, the NGOs wrote to families explaining that a research project was in process and seeking interested participants. Those guardians who responded positively were invited to participate in the study and asked to sign consent forms permitting the researchers to talk to their children. Communicating with children, particularly with children experiencing disadvantage, is problematic because there can be learning difficulties, behavioural problems and trust issues involved. All of these became apparent in the course of the fieldwork. At all times, the researchers were conscious of the need to employ language, actions and a demeanour that was child appropriate, and also to avoid pre-labeling children as 'disadvantaged'. Every effort was made to focus discussions on the holiday experience, without highlighting the relative disadvantages which were a reality of their lives or influencing the children's perceptions of their lives.

\section{The benefits experienced}

The study's central research question was how access to an annual holiday can contribute to quality of life and help combat social exclusion for children, and the families of children, experiencing social exclusion. This section begins by giving some insights into the quality of life being experienced by the study participants in their home places. It then moves to identify and discuss the short-term benefits associated with holidaying both for the children themselves and for their families. Finally, it goes on to detail some of the longer-term benefits.

\section{Summer-time living at home}

The study was largely concerned with summer-time living, a time which Gill and Wellington, (2003) described as being one of survival and of heightened exclusion. An early finding was that children and their guardians tended to speak negatively about their home environments. Boredom was a universal theme and the children's daily summer lives tended to be highly unstructured with daily routines that contained little variety or order. Children and guardians were at one in considering their home environments to offer few facilities and few opportunities to engage in structured recreational activities. Children explained how: 'You don't do anything here, just sit around all day, that's all ... 
you're real bored and all, you've nothing else to do' (teenage girl) and said how they love:

'to get out of here ... yeah, because we've nothing, nothing at all to do around here ... you'd sit around and you'd get real fat from just sitting around here because you're going up to MacDonalds every day, that's what I do be like' (teenage girl).

Many of the routines and supports that structure families' lives during the school term are missing in summer-time and this creates a marked void. Missing too are many extracurricular activities that run throughout term time but cease during the school holidays. In consequence, during the day-time, the children studied tended to engage in passive, indoor activities like watching television and playing on their play-stations. They played football a lot and simply 'hung around' inside their homes and out on the streets with their friends. Some children were out at night-time as well. As one young boy explained:

'yeah, in the day it's crap, at night it's good. People do be out all hours, and like we do be having a game of football or something 'til 4am. Sometimes at the weekend, eh like there would be fights and all, gangs and ... but the odd robbed car now is good' (laughing) (young boy).

Violence, conflict and aggression of varying scales were prevailing characteristics of the home environment. Without exception, children across the six study areas were exposed to such socially deviant practices as alcoholism, violence and bullying, drug taking and drug dealing, criminality of various kinds including stealing cars, burning cars and joyriding. These practices varied in their prevalence between areas, but some combination was evident in all. Sometimes these practices were so embedded as to be the norm and children and guardians seemed not to perceive them as risk factors. A further striking finding concerned the extent to which the children's geographical worlds were very limited. They tended to move out of their home environments only infrequently and their experience of other parts of Dublin, much less other parts of Ireland, was very 
modest. Even within their home place, which might have constituted a large sprawling housing estate, or a series of houses in rows, their association was with one street, one square, or one cul-de-sac, as opposed to the area in its entirety. Equally, their social worlds were very limited. There was a marked interaction with members of the extended family, many of whom lived in relative proximity to the families studied. However, beyond playing with their relatives, children seemed to play consistently with the children who lived in their immediate vicinity all the time. The children's limited spatial worlds contrasted sharply with their virtual connectivity to other places. Many of the older children interviewed had multiple communication tools in the form of ipods, access to internet chat rooms, Bebo, televisions, play-stations and mobile phones. The prevalence of such sophisticated material possessions belies the disadvantaged conditions that can characterize these children's lives. As one key informant explained:

'some (children in the area) are in terrible circumstances. There is still a lot of poverty around. In the past, you know, specifically economic poverty, there was a shortage of money. Now there is a certain amount of that, but it's really the whole family structure has broken down, so that youngsters are in awful circumstances really'.

\section{The temporary relief of going on holidays}

In the context of the foregoing, it is not surprising that the ability to get a temporary release from the routine home environment was unreservedly prized. Quite simply, going on holidays functioned as a relief. Children liked getting away for a while. As one young boy explained: 'ah, I thought it was good. Getting out of *** for a while ... something else to do for a change on the summer holidays'. Negative conditions prevailing within the home environments created a series of push factors, encouraging the children to leave. This finding echoes existing research like that of Haukeland (1990) who highlighted the strong influence of push factors. These factors were largely rooted in core problems: 'because there's too much drugs and all around it, everybody, just too much trouble and all there is around' (young boy); 'all the drugs, there's too much on the street' (young girl); because it means getting 'a bit of peace from everybody ... the area, I don't like my area, don't like it, fights every night and everything, you can't get proper 
sleep, fights on the street and the train station and the trains go by and they rattle the house and all like that, love to just move away' (teenage boy). For guardians too, the need to give their children a break was widely acknowledged: 'get them off the road' ... 'get away from the flats' ... 'anything is better than these flats' ... 'it got them out of this area, that's important'.

For the children, life on holiday was clearly different from life at home. While being at home in summer-time meant passing a great deal of time in unstructured and unvaried ways, holidays were action-packed, activity-filled and highly structured. This created a strong pull factor, strongly motivating the children to want to holiday. A recurring theme was that, on holidays, 'everything is different from home'. For one young girl 'it's a lot different from home and you get to make new friends... they have plenty more things to do and you get to go to the beach everyday'. Another young girl said, 'I would go every week ... because it's very good down there. You would rather live down there than live up in these flats'; her elder brother concurred, adding, 'I wish we lived down near Balbriggan' . In a later stage in the interview, when asked whether they would like to go on a Sunshine Holiday ${ }^{\mathrm{ii}}$ again, the same siblings responded: Brother: 'Yeah, I want to go next year and the year after as well'; Sister: 'I want to go for my whole life'.

Unlike the wider home environment, which several guardians described as being out of control, with neighboring children acting without parental supervision and criminal activities like car theft, joy riding, drug dealing and drug use prevalent, the holiday environment was highly regulated. Children were well cared for and fed at regular intervals. While many of the children disliked the routine of having to get up early in the morning, in general they seemed to accept the other structures imposed. The importance of routine and structures was alluded to by several key informants who spoke about how children:

'enjoy structure ... and it's good for them, you know, just being on time and getting teams together... They got to go to the shops, they had a certain length of time ... and then they were back. They could have their mobile 
phones in the evenings to send a few texts but then they were taken back off them again' (social worker).

\section{The fun of it all: a time for children to be children}

A key element of difference created by the holiday lay in the fun provided. The preholiday interviews with children identified the tremendous sense of anticipation with which children await the arrival of the letter announcing that they have a place on the holiday and again as they await their departure date. This echoes existing research findings such as those of Gilbert and Abdullah (2002) who wrote about the importance of anticipation. One guardian explained how: 'there does be great excitement. They do wait on their card in the letter box and then they're running up the road, running down the road telling one another they got the card' (the 'card' contained the confirmation that they had secured a holiday place). All but one of the children interviewed/surveyed postholiday claimed to have had thoroughly enjoyed the experience and there was a great deal of consistency in what was reported as being enjoyable. The provision of diverse and varied activities was enormously popular. For the older children these included abseiling, rock climbing, canoeing, horse-riding, sight-seeing and eating out. Most of these activities were rarely if ever available outside of the holiday context. For the younger ones it meant going to the beach, to playgrounds and activity centres, crab hunting and sports tournaments. These activities facilitated simple opportunities for free play and fun, opportunities that some of these children have all too infrequently.

A key argument made here is that the ability to have fun, in effect, to be a child, is an important contributor to a child's sense of well-being. The holidays were structured so as to create the conditions where children could be children. In essence, the organizers provided a series of structures and supports that consistently met children needs. Daily routines were established. The children had set bed-times that were adhered to, and set times for getting up; meals and snacks were provided at the same time every day, clearly

explained rules were established and operationalised around expected behaviour, and children who could not keep those rules experienced penalties that could (and did for a 
small minority) culminate in being sent home. An important dimension of this routine was that children knew that these supports were in place. They could rely on, and relax in, the knowledge that there was a consistent delivery of e.g. rest periods, meals and standards of behaviour. The mere fact that the children were given 'time targets' which they themselves could realistically meet created a sense of purpose, control and indeed achievement for the children. It also created a great deal of pleasure: holiday time, as deliberately constructed by the holiday organisers, was infinitely preferable to routine home time, where for many, summer days stretched out interminably without purpose, and were marked by 'hanging around' and boredom.

The data revealed the extent to which some of these children are routinely asked to assume responsibility beyond their years. Some act as carers of siblings, others worry about the welfare of their guardian, while others live with adult carers who are not always able to adequately attend to their needs. Some guardians acknowledged this, with one mother reporting how her son got upset going on the bus (to go on holiday): 'he was worried about me because his father was there so automatically he was sort of "ma, are you alright?", you know, he sort of tries to protect me even though he is only 11'. Several others explained how the older children are expected to look out for the younger ones while outside the home: 'the little young fellow out playing and he (older brother) always watches him' (mother). Some children were able to articulate what for them was a welcome change, and explained that going on holiday meant they could: 'Get away from your ma, from cleaning up' (young girl), 'get a day without me nephew and niece' (teenage girl), and didn't have 'to mind your little brother or your little sister' (young girl). Much of this was reinforced in the key informant interviews who frequently argued that the children in question are often forced to assume adult roles and take on a great deal at very young ages. When asked for her views on the benefits of one of the holidays being studied, a social worker who also acted as a holiday leader responded:

'that they get to go and be children for a week, they don't have those outside pressures, they don't have to worry about getting somebody else up for school in the morning, they don't have to worry about what their parents are 
or aren't doing. I suppose that they get a break from what are often really difficult home environments'.

Another related finding, one that pertained particularly to young males, was that the holiday environment relieved young people of the pressures that they can routinely face to act out particular roles. One key informant, a Sunshine Fund volunteer, spoke of how the holiday context, by stimulating the children with age- and socially-appropriate activities and challenges, enables young boys to be themselves and curtails routinely felt pressures to live up to the image of being a 'hard man'. This suggestion was echoed by a community worker: 'lads, they have to be tough and rough maybe to survive with certain sections here, but when they go away (on holidays) that all dissipates, they relax ... as the time is going on they're just becoming so relaxed in themselves'.

\section{Broadening social horizons}

As previously mentioned, the children studied have limited social worlds. They tend to have little exposure to different people and so to different lifestyles. The importance of 'making new friends' emerged strongly in the pre-holiday interviews with children who had already been on a holiday with one of the NGOs. They spoke of looking forward to making new friends and of hoping to re-connect with friends already made on previous holidays. It was also one of the strongest themes to emerge in the post-holiday questionnaires and interviews, with the vast majority of children citing 'making friends' as being one of the holiday's most enjoyable aspects. For several older children, an important outcome of the holiday was obtaining mobile phone numbers of fellow holiday-makers and keeping in contact through texting and meeting up post-holiday. In the words of one teenage girl '(I) made loads of new friends, we made friends with everyone down there ... I got all their numbers and we're meeting up Saturday in town' .

It is significant to note that often the new friends encountered on holiday actually lived in

relative proximity to each other, sometimes only a few kilometres away, yet it was only through the intervention of the holiday that children managed to attain this modest broadening of their social worlds. This is true even of children living in the same estate, 
who did not know each other very well before a holiday. One key informant, a holiday leader, reported how a number of children who developed friendships on holidays from being placed together in joint accommodation, or in groups for trips, maintained these friendships long after the holiday. Thus, the social interactions and inclusion fostered on holiday extended beyond the period of the holiday itself. Inclusion was further maintained through the shared reported of experiences that followed on from the practice of holidaying. Ridge (2000) and Van de Hoek (2005) have discussed how participating in holidaying functions as an important social statement. This was borne out here in the words of one boy (teenager), for whom going on holiday meant 'so you can tell them about it ... normally we would just be sitting there ... yeah, you want to be saying ah I did this ...' Accessing a holiday means being able to join in on the shared reporting of summer holiday activities that marks the return to school and the resumption of term-time activities. This ability to talk about having had a holiday may be as important as actually having had one.

\section{Building self-esteem}

The difficulties that children living in disadvantaged circumstances experience in terms of developing self-esteem and defining appropriate roles for themselves are well documented (Prelow, Weaver and Swenson 2006). In this study these difficulties, including prevalent bullying, were described consistently by key informants and guardians. In addition, some children were already well aware that they faced an uphill struggle in gaining affirmation from significant others. One young teenage boy explained his status in school: 'I should have got put into A4 but I got put into A2, that's the dumb class in my school and I can't get changed now ... we're all dumb in my class'. In this context, a significant finding of the study was the important role that the holidays play in affirming self-worth and developing self-esteem. In general, the holidays provided a very positive environment for the children to test their abilities without fear of being humiliated. A marked emphasis was placed on praising children, acknowledging and rewarding effort and encouraging children to challenge themselves. It was clear that this atmosphere of 'positive expectations' impacts well on how children view themselves and this was reinforced by the equally positive emphasis on the importance of taking part as 
opposed to simply 'succeeding'. The organisers believed success to be about more than just 'winning': i.e. achievement and success were all about taking part and making an effort.

Prizes were distributed on the basis of participation as much as success and conscious efforts were made to ensure that all children won a prize. These prizes were highly valued by the children who often were very keen to report (during interviews) how they had won trophies, medals and prizes for sport, art, dancing, sand-castle building and other varied activities. Frequently, post-holiday interviews with adults were interrupted by young children coming over to show off their prizes. The delight that children took in these rewards was obvious and repeatedly guardians spoke about how their children loved getting them. The affirming role of prize-giving was emphasized frequently by guardians: 'Oh the trophies (laughing) that's all you hear about is the trophies, yeah' (mother). As interviewers, we often saw the trophies taking pride of place in the families' living spaces, thus continuing to re-affirm the children's pride in their achievements. Repeatedly, the contrast with the home environment was highlighted, with guardians explaining how 'you never really hear her getting a trophy for anything' and 'you wouldn't get anything like that up here' (mother).

In all of the holidays studied, a number of mechanisms were consistently employed to boost children's self-image. These included getting to know each child by name and using their names all the time, giving children individual attention, giving them scope to make choices and minor decisions and listing children's names as part of sports teams on boards. While these mechanisms resulted in children being identified as valued individuals, in the process they were prompted to acknowledge and understand that they were part of a group that extended beyond themselves. Children were encouraged to think that what they did mattered, that their actions could affect other people around them (for good or for bad), and that they had the ability to choose what those actions might be. Acknowledging their roles and contributions was manifest in naming achievements (e.g. names were inscribed on trophies for the 'best person on holidays'), publicly praising the strengths and qualities of each young person, hanging children's paintings on the walls 
each evening, and videoing them at play/ in action for showing to all in the evenings. Boosting self-esteem was one of the key benefits identified by a majority of guardians. In the words of one grandmother/guardian, the holiday 'creates self-esteem and gives them courage to go out then with their friends instead of being bullied into the one place'.

Significantly, the holidays studied provided activities that were designed not only to entertain but to diversify the children's routine experiences by offering them opportunities not normally available to them and to challenge them in appropriate ways. At the outset, all of the holidays involved the children in travel experiences. The travel components varied from taking coach trips to the other side of the city, or to neighbouring counties, to taking an airplane/ferry to a different country. In all cases, there was novelty and excitement involved as in the main, these children's routine lives unfolded in limited spatial worlds. Frequently, children spoke about their pleasure in 'trying new things', and very often they were referring to the sporting/outdoor recreation arena. For young children this might have involved trying to swim, or taking responsibility for a team venture; for older children it might have been applying themselves to the task of horse-riding or abseiling for the first time. Involvement in these activities engaged the children with forms of recreation that many of their peers in mainstream society routinely experience through their after-school, extra-curricular classes, clubs and networks (e.g. swimming, horse-riding, orienteering, soccer etc.). Thus, while many of these experiences might be considered a normal part of the average child's experience in contemporary Ireland, for those studied, these were mainly new and 'special' experiences, relative to their standard lifestyles. In addition, children were offered more relaxing, fun, and/or artistic activities like trips to the beach, gathering to watch films, doing arts and craft activities, or in the case of one of the holidays, eating out in a restaurant and going to watch a UK premier league football match.

Rising to these challenges earned praise, admiration, reinforcement and encouragement from the holiday leaders who encouraged a very positive, affirmative atmosphere, and a prevailing expectation that children could succeed, in a culture of 'trying one's best'. This atmosphere contrasted with that depicted in the data gathered from key informants 
and guardians, where prevailing expectations and future aspirations for children tended to be defined relative to negativities in the home environment. Guardians, for example, spoke in terms of surviving their situation, of hoping that their children would not get into difficulties with drugs/violence/crime etc. yet expecting that this was almost inevitable.

Sometimes, particularly in one of the holiday organizations studied, opportunities were provided for older children to act as mentors for the younger cohort. This mentoring role was not particularly onerous, and did not represent a burden in any sense, rather it was intended to boost the self confidence of the child in question. At the same time it served to offer a positive role model for younger children.

\section{Learning new skills}

The holidays were found to provide a range of opportunities to try out new activities generally unavailable to the children in their home environment. The post-holiday data collected showed that this was central to the enjoyment of the holiday for a majority of the children. With very few exceptions they thoroughly enjoyed: 'doing stuff every day and doing things that you didn't do before, all that is great, trying new things' (teenage girl); 'all the different things, rock climbing and canoeing, even though I can't swim, trying new things' (teenage boy). Aside from the pure enjoyment that participating in these activities engendered, many of them also provided opportunities to take risks in controlled and appropriate contexts. The significance of this benefit lies in the fact that for many of the children studied, the home environments in which they find themselves can often promote tendencies to engage in inappropriate risk-taking behavior.

On holidays children could challenge and test themselves with positive results. Existing literature on the value of outdoor recreation argues its benefits in respect of self esteem and self-image (Gray 1997), especially, perhaps, in the case of girls. While girls can be reluctant to participate (Gray 1997, Henderson and Hickerson 2007) outdoor education for girls has been positively linked to personal development (Baker-Graham 1999), and female involvement in outdoor adventure settings has been found to build self-trust and self-worth (Pohl, Borrie and Patterson 2000). This study found instances to reflect these 
extant findings. For example, one teenage girl explained how she had been afraid to do abseiling on holidays the previous year but had managed to do it this year. Several children managed to try water-based activities like canoeing even though they could not swim. In a different context, one young girl pointed out that staging plays in the eveningtimes helped children overcome stage fright. Allied to this was the frequent suggestion from guardians that going on holidays encouraged children to develop a series of skills connected to self-reliance and independence. There was a general sense among many guardians that having time away on their own was positive. In explaining that she felt it was a good idea for her children to go on holiday one mother stated:

'Oh God, yes, yes, 'cause they've never been anywhere, you know what I mean, like, I can't afford to bring them away on a holiday and I think it's good for them, to have their own, you know, their own time away from parents, I think it gives them a lift to go on holiday' (mother).

Without exception, guardians thought that it was good for their children to go on holiday. They explained how the holiday helps children 'come out of themselves'. One mother explained how she thought the holiday experience had helped one of her twin sons become more independent of his brother. Many spoke about how it helped develop selfreliance and responsibility: children had to pack their bags, take care of themselves in the absence of having recourse to their guardians, get along with different children and make new friends, adapt to a new set of domestic regulations and structures and manage their pocket money. Guardians thought that the holiday experience was useful in helping children to 'grow up', to develop maturity, to become more confident, to express themselves more clearly and to develop social interaction skills. One mother, whose daughter had been designated to act as a leader during the holiday, spoke of how the holiday had allowed her daughter to flourish and to develop her innate leadership skills. The value of the holidays in helping children develop coping mechanisms and greater independence and to become more socially adept at mixing with new people and handling new social situations was reinforced repeatedly in the interviews with key informants. 


\section{Quality Relationships with significant adults}

Another key finding to emerge from the study was the quality of the relationships that children developed with the holiday leaders. The leaders frequently emerged as being central to the children's enjoyment of the holiday. This was the case for both boys and girls. Before the holidays, children spoke of looking forward to meeting them and hoped that particular leaders, familiar to them from previous holidays, would be there this year. They consistently spoke in positive terms about the leaders: 'they're real nice and they'd give you time to do something if you needed to do it, that's what I liked about them as well, they weren't cranky or anything' (teenage girl); 'they were very nice, well, they just look after you well' (teenage girl); 'got on well with the leaders, especially **, they do things with you. Will miss them' (teenage boy); 'they are great because they get involved, they ask you do you want to do this or that, you get to choose instead of them choosing for you' (teenage boy).

The extent to which the children connected with the leaders was reinforced in the interviews with guardians. One guardian spoke about how a leader had lent a mobile phone to her son. This she interpreted to be not only an act of kindness but also an act of trust and respect, something that was not lost on her son. It was quite common for children to develop a bond with particular leaders. These leaders would then figure prominently in children's stories about the holiday. Some children reported missing the leaders after they went home. One mother reported how her son had spent hours crying on his return from the previous holiday because he missed the leader so much. Some guardians seemed surprised at how their children developed a bond with the leaders, with one mother commenting on how 'they actually hug the leaders and all when they are leaving'.

The significance of this finding possibly lies in the fact that the leader figure may be filling a vacuum present in the children's home life. This was the view of a number of key informants. A majority of the children studied lived with the absence of one or both parents. If it was the case that one parent was absent, this was usually the father. In this 
context, the leader acted as a significant adult who provided, albeit temporarily, social interaction, care, attention, interest and encouragement. In effect, the leader, if a male, sometimes constituted, as one boy put it, a 'letting on dad'. One mother spoke about her son's relationship with one particular leader: 'fantastic, made him feel special, with not being a man in the house it kind of gave him somebody that thought something of him, just constantly ma all the time so ...'

Beyond this, the quality of the children's relationships with the leaders is clearly significant. In writing generically about the benefits of holidaying, Richards (1998) commented that the quality of time spent on holiday is different to non-holiday time. This was definitely the case here, and the presence and actions of the leaders was one of the key factors contributing to the creation of quality experiences for the children. As discussed earlier, the leaders were proactive in engaging, encouraging, affirming and supporting the children in a myriad of ways and in a determinedly positive atmosphere. The leaders had voluntarily given of their time for the 5 / 7 day duration of the holiday and during this period they were fully focused on attending to the children's needs. It was abundantly clear from interview data and from observation work undertaken during one of the holidays that they forged warm ties with the children in ways that clearly added to the latter's sense of both security and enjoyment during the holiday. As one single mother explained, the leaders 'have so much time for them and I think they give them individual time ... they just love it, really love it'. Most of the leaders were young and while they had a role in monitoring behaviour, disciplinary controls (if required) were the responsibility of one 'Head' leader on any given holiday. For some of these children for whom quasi-parental roles were the norm at home (e.g. minding siblings, preparing meals, worrying about domestic matters), the leaders relieved them of responsibilities, thus enabling them to relax into childhood modes.

In all cases, the leaders provided a strong positive role model which left an impression on the children. One of the mothers explained how her son 'took a shine to ** and now he wants to go to the school that ** went to and done his Leaving' (final second level school exam). In the case of one of the holidays studied, the leaders were from the local 
community. This meant that children would continue to see them in the vicinity. For one mother this was very positive as 'it's good for my sons to be around good local lads'.

\section{Behavioral change}

Many guardians reported some form of behavioral change in their children post-holiday, all of it positive. They used adjectives including 'happy', 'excited' and 'animated' to explain their children's mood on return home. Without exception, they thought the holiday had done their children a lot of good and considered their children to be 'in great form', 'more alive', to have 'come out of themselves' and to be 'just full of themselves'.

The holidays were attributed with 'bringing them on a lot' and with giving them 'rosy cheeks' from all the activities. One child (young girl) reported how 'I felt like much better like, healthier, Yeah I did ... you're running around and all'. It was reported that some children came home 'more relaxed'; one mother found that the holiday had 'settled him (her son) down ... he can be bold'. A number of them reported that their children were acting more responsibly since they came back. Two guardians reported that their sons were helping out more around the house in the aftermath of the holiday. Interestingly, a few guardians acknowledged their own need to learn to give their children more independence. Due to a combination of circumstances including lone parenting and risks in the home environment, some parents may be overprotective of their children. There was acknowledgement that the provision of the holiday facilitated a healthy, controlled and temporary 'letting go' of their children, in a way that was mutually beneficial for both guardians and children

\section{Benefits for the Wider Family}

A further important finding of this study is that the benefits created by the holiday seemed to spread out into the wider family in the immediate post-holiday period. This was the case even though none of the families studied had managed to avail of a holiday for all of their children. Nevertheless, the fact that one or more of their children had had a break from the home seemed to reinvigorate the family as a whole. It seemed, for example, that intra-family relationships were strengthened by the separation. With a 
small number of exceptions, children had missed their parents/guardians and siblings, and guardians had missed their children. The mutual recognition that each had been missed was significant in reaffirming the ties between them. This was especially the case for several children who seemed insecure about whether they would be missed or not. Children reported a variety of feelings about being home again. Most were happy to be home, but irrespective of how they felt, their return, generally speaking, reinvigorated the home environment. Guardians explained how they came home happy, with stories to tell and prizes to display. One mother thought that this helped parents see their children in a new light. This sense was reinforced by a social worker who saw a great benefit in

'the parents being able to see that they're (the children) capable of living apart from them and coming back with good feedback. When parents hear good things about their children they behave more positively towards them'

Certainly, communication within the families was improved because of the flow of news generated by the holiday. There was freshness to the relationship with communication being instigated by the child and responded to by the guardian, rather than the more usual vice-versa scenario. It was clear that guardians and children were better able to interrelate more positively, having had a break from each other.

\section{Longer-Term Benefits}

The key informants interviewed during the course of this study were at one in asserting that behavioral change cannot be affected through a holiday of five or seven days duration. Indeed, the agencies themselves were quite clear that behavioral change was not being sought through the mechanism of short-term holiday provision. Equally, this study did not set out to identify the long-term benefits of providing child-centred holidays to

children experiencing disadvantage. Nevertheless it identified a number of indicators which suggest that the benefits of such holidays extend well beyond the duration of the holiday itself. The first related to the sense of anticipation with which children view the holiday from one year to the next. Children, guardians and the holiday provider 
volunteers were at one in reporting how children looked forward to the break away. One mother related a conversation with a volunteer from a locally-based NGO: 'Mary, he said, I just want to ask you, are your children interested in going (on holidays) this year? Interested, I said, they haven't stopped talking about it since last year'.

It was also clear that the holidays live on in the memories of the children long after the holiday is over. The guardians who participated in this study included a number who had themselves experienced a Sunshine Holiday as children. All of these remembered and spoke fondly of these holidays. One of the social workers interviewed spoke about encountering older children through the course of her work and of how they remembered their Sunshine Holiday as a happy time in their lives. She went on to argue that for the children involved in the current study, longer-term benefits might include learning to value and maintain friendship, treating people well and positively and not engaging in bullying. 


\section{Conclusions}

Holidaying is now widely regarded as a normal, mainstream social practice (Urry 1995, Smith and Hughes 1999, Holden 2005). Holidaying yields multiple benefits that meet a range of human needs, yet it would seem that sizeable minorities, in even the wealthiest of countries, are denied these benefits because they are unable to access an annual holiday. Some researchers even argue that the benefits of a holiday might be more valuable to those who cannot access one: those from deprived/disadvantaged backgrounds, and those who are isolated, stressed, dependent, ill or materially deprived, as these people are most in need of a holiday (Hughes 1991, Smith and Hughes 1999). Extant research shows that a lack of financial means, while not the only constraint, is the most pervasive and people experiencing social exclusion are unlikely to be able to participate in holidaying if dependent on their own resources. According to Van Raaji and Francken (1984), in a situation where economic resources are in short supply, older people and those of low status are more inclined to forego a vacation entirely, while younger and middle class people are more prone to choose a cheaper form of holiday (cited in Haukeland, 1990).

Those who are unable to participate in holidaying experience a form of social exclusion. Recalling Atkinson (1998), relativity is a key concept here. To be unable to engage in holidaying means to differ from the norm. Excluded people are doubly disadvantaged in that they cannot enjoy the many benefits of holidaying, but as Van der Hoek (2005) pointed out, neither can they enjoy the sense of inclusion and status enhancement that comes from the post-holiday sharing of experiences with social peers. In brief, the argument forwarded here is not that a widening of access to holidaying will automatically serve to eliminate social exclusion, rather it is that enhanced opportunities to engage in holidaying offer possibilities for reducing it. It was clear from this study that the adults involved (as guardians of the children studied) were aware that they were socially excluded when it came to holidaying. They knew that most people in Irish society holiday and they felt that they were failing their children in not being able to give them this 'normal' lifestyle opportunity. It was on this basis that guardians welcomed the 
involvement of the NGOs as a parenting support, acknowledging the fact that the NGO holiday providers were offering their children something that lay beyond their own grasp. It was equally clear that the holidaying opportunity given to children promoted social inclusion in several ways: it brought them into contact with standard social practices and varied their social settings in ways that they only rarely experience (e.g. making new friends, interacting with people outside their normal social sphere, gaining respect from peers through achievement, eating out in restaurants, adhering to standard codes of group behaviour, etc.). While this study focused on the 'here and now' of the holiday period itself, there were indications that the skills fostered, the personal development engendered and the behaviours encouraged during the holiday endured beyond that time period and transferred into social settings and social practices routinely associated with the children's home lifestyles. While much further research is needed on this area, it seems reasonable to suggest that the social inclusion effects promoted through opportunities to engage in the diverse activities involved in holidaying are transferable.

In addition, children hugely valued the social inclusiveness fostered through the friendships and social interactions they developed while on holidays. Often, they carried these friendships with them back to their home places, intending to maintain connections through telephone contact and occasional meetings in the short term, as well as hoping to renew friendships on subsequent holidays, if given the opportunity to partake again in the future. It was equally clear that children valued being able to talk about their holiday activities with their peers on their return home. The sense of social connection that lay in able to talk about their experience of being socially included cannot be overstated.

The research attributed a whole series of benefits to holidaying for the subjects under study. The findings suggest that the most significant benefit for the children studied lay in the fact that the holiday took them away from their home environments which are characterised by 'a combination of linked problems such as unemployment, poor skills, low incomes, poor housing, high crime environments, bad health and family breakdown', to restate the UK, Department for Social Security's (1999: 23) earlier cited definition of social exclusion. Clearly, the quality of time spent on the holiday under study was 
immeasurably better than that generally experienced by the children in their routine home lives. The holiday suppliers worked hard to deliver quality time for the children through the norms and expectations they created around 'life on holiday' and in the structures and mechanisms they devised to organize daily routines. Everything was intended to enable the children to relax, have fun, make friends, develop new relationships and new skills, and experience different ways of living in an environment that was largely happy, positive and supportive. As such, the research broadly supports existing knowledge about the positive contribution that holidaying makes to well-being, relaxation, social interaction and social bonding found in the general literature (Hobson and Dietrich 1994, Richards 1998) in that dealing with people experiencing disadvantage (Hughes 1991, Voysey 2000) as well as in that which deals specifically with families and youth/children in disadvantaged contexts (Lewis 2001, Hazel 2005, Corlyon and La Placa 2006).

One question posed early on in this article asked how engagement in holidaying might help to develop social capital. In this regard, there is little doubt that a key benefit for the children studied lay in the social networking and connectivity fostered through the holiday. Not only did they meet new peers and make new friends, they developed positive relationships with older children who acted as role models, and quality relationships with holiday leaders who affirmed, encouraged and supported them. Several data sources, particularly from guardians and social workers, suggested that these developments sustain well into the post-holiday period, effectively becoming resources that individual children can continue to draw on long after the holiday has ended. This was particularly the case when there was some tangible link between the temporary holiday and the normal routine of the child's life at home. Examples of this include instances where holiday leaders lived, or worked in, the same place as the children, leading some guardians to express delight about the role model effect evident as the children continued to meet the leaders once back in the home environment. Sometimes, these leaders had not been known to the children before the holiday.

As already stated, the findings reported here pertain to one particular type of holiday provision: a structured, child-centred, child-only, group holiday. This is quite an unusual 
model in a European context where state supported 'tourism for all' provision is more likely to facilitate family holidays, but in Ireland it is prevalent. An obvious area for further research lies in investigating the relative merits of different types and models, lengths and frequencies of holidays. It is likely that different types of holiday may produce qualitatively different outcomes. Data collected anecdotally during this research gave limited insights into the relative merits of different types of holidays. Quite often key informants contrasted the value of the holidays under study with the disadvantages they associated with the self-funded, self-organised holidays increasingly being taken by families living in some of the areas studied. In these cases, it was argued that the dysfunctional dimensions of the routine home environment tended to be simply transferred to a different location. So for example, children's experiences on such holidays might be limited to babysitting their siblings in a holiday apartment while their guardians socialise; or it may be that guardians' misuse of alcohol worsens in holiday locations where alcohol costs much less than in Ireland. Occasionally, children themselves also alluded to this type of negative holiday experience. Some of the guardians also made reference to previous experiences of a family holiday scheme provided on an ad-hoc basis by an NGO working in Ireland. In this scheme families are funded by the NGO to holiday in specific domestic seaside resorts. However, the problem as aired by a number of the guardians, is that these resorts can actually add to a family's problems because they provide easy access to gambling opportunities and to tempting but costly children's attractions like fairs and amusement parks.

Hinted at here is the suggestion that a wide variety of skills and abilities are required in order to engage effectively in the practice of holidaying. Already, research has suggested that improving financial means does not necessarily lead to increased participation (Baum 2006), rather a diverse range of social, cultural, technological and other skills are also needed. Yet, the question as to precisely what skills are needed remains to be answered. So too, remain questions relating to how financial constraints operate in conjunction with other types of constraints in limiting access to holidaying and its attendant benefits. 
This study clearly found that the benefits of holidaying for the children studied were not confined to the actual duration of the holiday itself. However, further investigation is needed to ascertain how the anticipation of the holiday before the event, and the memories and behavior modifications associated with the holiday, continue to be meaningful afterwards. In addition, more needs to be known about how the relative length and regularity of holidaying enhances longer term effects? Are children particularly susceptible to longer term benefits than adults, for example? Many questions could usefully be posed around this issue.

The research reported here is rooted in the Irish context where the state places little value, beyond economic value, on holidaying. The impetus for undertaking the research was to draw attention to the social exclusionist nature of holidaying in Ireland and to stimulate policy debate and ultimately policy development in the area. In an Irish context, this constitutes a completely under-researched area. Thus, the research reported here is very much exploratory in nature and intent on raising issues for further debate. In policy terms, the paper argues that an inability to afford an annual holiday is an integral part of what it means to experience disadvantage and social exclusion in contemporary Ireland. It argues that a need exists for policy makers and practitioners active within social welfare, economic, health, education and tourism domains to acknowledge that holiday participation can yield a series of benefits at personal, inter-personal and societal levels. It further argues that holiday provision constitutes an innovative response capable of complementing a broader range of social welfare inspired interventions designed to address the complex realities of poverty. Rising to the challenge of policy-making in this area is important if, following Erikson (2007: 265), policy-makers are concerned to ensure that Ireland becomes 'not only a richer but also a better society to live in' and that Irish society becomes a nation 'where people not only earn more but also have better lives'. 


\section{References}

Atkinson, A. B. (1998). Social exclusion, poverty and unemployment, in, Atkinson, A. B. and Hills, J. (eds.) Exclusion, Employment and Opportunity, CASE paper 4, Centre for Analysis of Social Exclusion, London School of Economics.

Baum, T. (2006). Low-cost air travel: social inclusion or social exclusion?, Tourism, Culture \& Communication, Vol 7., p.49-56.

Brimacombe, M. (2003). Wish you were here? New Start Magazine, www.newstartmaga.co.uk

Canadian Council on Social Development (1984). Not Enough - the Meaning and Measurement of Poverty in Canada, CCSD Ottawa

Combat Poverty Agency (2000). Richer but more unequal: the distribution of income in Ireland, Poverty Briefing No. 10, Spring

Corlyon, J. and La Placa, V. (2006). holidays for Families in Need: Policies and Practice in the UK - Final Report to the Family Holiday Association, Policy Research Bureau.

Central Statistics Office (2007). Household Travel Survey, Q4 2006

Davidson, P. (1996). The holiday and work experience of young women with children, Leisure Studies, 15, 89-103.

Ecclestone, K. and Field, K. (2003). Promoting social capital in a 'risk society': a new approach to emancipatory learning or new moral authoritarianism? British Journal of Sociology of Education, 24, 267-282.

English Tourism Board (1989). Tourism for All. A report of the working party chaired by Mary Baker

English Tourist Board (1985). Holiday Motivations - Special Report, London: ETB.

Erikson, R. (2007). Soaring in the best of times? In Fahey, T., Russell, H., Whelan, C. T. (eds.) Best of Times: the Social Impact of the Celtic Tiger, Dublin: IPA. 
Eurobarometer (1998). Europeans and their Holidays, Brussels: European Commission DG XXIII Enterprise policy, Distributive Trades, Tourism and Cooperatives.

European Commission (2001). Outcome of the European Ministerial Conference 'Tourism for All', http://europa.eu.int/comm./enterprise/services/tourism/policyareas/bruges_conference.htm. Accessed 25/05/2006

Gilbert, D. and Abdullah, J. (2002) A study of the impact of the expectations of a holiday on an individual's sense of well-being, Journal of Vacation Marketing, 8 (4), 352-361.

Gill, O. and Wellington, T. (2003) Wish you Were Here: Child Poverty and Exclusion in the Summer Holidays. London: Barnardos.

Gray, T. (1997) Examining the roots of the outdoor education tree from a gender perspective. In Deeply rooted, Branching Out. 1972-1997. p.113-130.

Haukeland, J. (1990) Non-travellers: the flip side of motivations, Annals of Tourism Research, 17, (2) 172-184.

Hazel, N. (2005) Holidays for children and families in need: an exploration of the research and policy context for social tourism in the UK, Children \& Society, 19 (3) 225236.

Henderson, K.A. and Hickerson, B. (2007) Research update: women and recreation opportunities. Parks and Recreation, April, 26-29.

Higgins-Desbiolles, F. (2006). More than an 'industry': the forgotten power of tourism as a social force, Tourism Management, 27, 1192-1208.

Hobson, J.S.P. and Dietrich, U.C. (1994). Tourism, health and quality of life: challenging the responsibility of using the traditional tenets of sun, sea, sand and sex in tourism marketing, Journal of Travel and Tourism Marketing; 3(4), 21-38.

Holden, A. (2005). Tourism Studies and the Social Sciences. Oxon: Routledge. 
Hughes, H. (1991). Holidays and the economically disadvantaged, Tourism Management 12, (3), 193-196.

Ianniello, F (2006). 'Tourism pour tous'. Resultats du questionnaire: Etat des lieux et pratiques existantes dans l'UE. Paper presented at the social tourism - conference "Tourism for all : state of the play and existing practices in the EU" conference, January $17^{\text {th }} 2006$, Brussels.

Jolin, L. (2004). L'ambition du tourisme social: un tourisme pour tous, durable et solidaire, www.bits-int.org. accessed 26/05/2006.

Jones, S. (2005). Community-based ecotourism. The significance of social capital, Annals of Tourism Research, 32, (2) 303-324.

Lauprêtre, J. (2006). In France, One out of Three Children Still Doesn't Go Away on Holidays, l'Humanit; 24 June 2006. English version of article translated by Bolland accessible at www.humaniteinenglish.com/article217.html

Lewis, E. (2001). Evaluation of the Benefits of Recreational Holidays for Young People in Public Care, London: The National Children's Bureau.

Macbeth, J.; Carson, D. Northcote, J. (2004). Social capital, tourism and regional development: SPCC as a basis for innovation and sustainability. Current Issues in Tourism, 7, (6), 502-522.

Mack, J. and Lansey, S. (1985). Poor Britain, London: George Allen and Unwin.

Mathieson, A. R. and Wall, G. (1982). Tourism: Economic, Physical and Social Impacts Harlow: Longman.

Mergoupis, T. and Steuer, M. (2003). Holiday taking and income, Applied Economics, $35,269-284$.

Micklewright, J. (2002) Social Exclusion and Children: A European View for a US Debate, Innocenti Working Papers No.90, Florence: Innocenti Research Centre.

Pohl, S. L.; Borrie, W. T. and Patterson, M. E. (2000). Women, wilderness and everyday life: a documentation of the connection between wilderness recreation and women's everyday lives. Journal of Leisure Research, 32, (4), 415-435. 
Prelow, H. M.; Weaver, S. R. and Swenson, R. R. (2006). Competence, self-esteem, and coping efficacy as mediators of ecological risk and depressive symptoms in urban African American and European American youth, Journal of Youth Adolescence, 35, 507-517.

Richards, G. (1998). Time for a Holiday? Social Rights and International Tourism Consumption, Time and Society, Vol. 7 No. 1, p145-160 Seaton, A.V. (1992). Social Stratification in Tourism Choice and Experience since the War: Part 1, Tourism Management, 13, 1, 106-111.

Shaw, G. and Williams, A. (2002). Critical issues in tourism: a geographical perspective. Oxford: Blackwell Publishing.

Smith, V. (1998). The Relationship between Poverty, Holiday-taking and Social Policy (with specific reference to low-income families). PhD Thesis, Manchester Metropolitan University.

Smith, V. and Hughes, H. (1999). Disadvantaged families and the meaning of the holiday, International Journal of Tourism Research, 1, (2), 123-133.

Stephenson, J. (2000). Presentation at the launch of the LGA Tourism as a Tool for Social Inclusion Campaign, London: LGA.

Urry, J. (1995) Consuming Places, London: Routledge.

Van de Hoek, T. (2005) Through Children's Eyes. An Initial Study of Children's Personal Experiences and Coping Strategies Growing up Poor in the Netherlands. Innocenti Working Papers 2005-06. Florence: UNICEF.

Van Raaji, W.F. and Francken, D.A. (1984). Vacation Decisions, Activities and Satisfaction, Annals of Tourism Research; 11, (1), 101-112.

Voysey, K. (2000) Just What the Doctor Ordered - the Benefits of Taking Holidays, London: English Tourism Council. 
i The interview and focus group proceedings were all recorded and participants' contributions are quoted verbatim, complete with grammatical inaccuracies and the vernacularisms of English as spoken in certain parts of Dublin.

${ }^{11}$ Sunshine Holidays is the name of the holidays organised by the Sunshine Fund, a section of the NonGovernmental Organisation, the Saint Vincent de Paul. The Sunshine Fund has been organising childcentred holidays for disadvantaged Dublin children for some 80 years. 